\title{
Impacts of temperature and surface finish upon steam oxidation of austenitic steel TP347HFG
}

\author{
J. BOUVET, J. SUMNER, N.J. SIMMS* \\ Cranfield University, Cranfield, Bedfordshire, MK43 OAL, UK \\ *Corresponding author: n.j.simms@cranfield.ac.uk
}

Abstract

The effects of the steam oxidation process on an austenitic steel (TP347HFG) exposed under isothermal conditions between 600 and $800^{\circ} \mathrm{C}$ for up to 2500 hours have been investigated. Samples with both as-received and ground surfaces have been exposed and the impact of surface finish on the oxidation process analysed using scanning electron microscopy (SEM) with energy dispersive X-ray analysis (EDX). Exfoliated oxide flakes have also been examined to characterise their microstructures on fractured sections as well as external and spalled surfaces.

Microscopic analyses demonstrated that ground surfaces possess better steam oxidation resistance than as-received surfaces due to their ability to form a more protective chromiumrich layer. The formation of regions of thicker multi-layered oxides was noted on both types of surface finish, covering large areas on as-received surfaces and only nodules on ground surfaces (spreading with increasing exposure temperature and time).

Keywords: steam oxidation, exfoliation, surface finish, oxide morphology, austenitic steel. 


\section{Introduction}

To tackle climate change, it was agreed at the 2015 Paris Climate Conference (COP21) that renewable energy should represent at least $27 \%$ of energy production by 2030 and that energy efficiency should also be improved by at least $27 \%[1,2]$. In combustion systems based on the Rankine cycle, the steam working conditions directly affect plant efficiency. Thus, future fossil fuel fired combustion power plants using steam under Advanced UltraSupercritical conditions (up to 345 bars and $760^{\circ} \mathrm{C}$ [3]) will be able to achieve net plant efficiencies of $>50 \%$ in terms of Lower Heating Values (LHVs).

Fine grained austenitic steel TP347HFG is a possible candidate material for use in superheater and/or reheater tubes in parts of these systems. Grabke et al. [4] noted that a fine-grain structure possessed superior oxidation resistance compared to coarse-grain material, and illustrated the effect of surface finish on the steam oxidation process. It would appear that any surface finish that results in deformation of the material's surface is beneficial with regard to steam oxidation resistance [4,5]. Indeed the abundance of deformation and the proliferation of grain boundaries under the surface of a material enhances chromium diffusion to the samples' surface in order to quickly form a protective chromia layer [4].

It has been reported that at temperatures below $550^{\circ} \mathrm{C}$ mass change analyses show that austenitic steels such as TP347HFG follow a parabolic rate for about 10000 hours before transitioning to a linear rate [5]. However, during steam oxidation experiments at higher temperatures where mass change has been recorded [4-7], it has been difficult to predict the order of reaction due to oxide scale exfoliation. This exfoliation is a detrimental effect that happens during the cool-down of both samples and heat exchanger tubes. It can cause blockages of heat exchanger tubes and erosion of steam turbine components [6]. Sabau et al. [8] addressed the development of a model describing the exfoliation and regrowth of oxide scale developed on TP347HFG. However they noted that there was a lack of reported information regarding oxide growth, such as the evolution of oxide morphologies and voids in the oxide scale, as well as the characterization and quantification of oxide loss.

This paper reports observations of the morphology of oxides formed during steam oxidation of austenitic steel TP347HFG with two different surface finishes: "as-received" and ground. Scanning Electron Microscopy (SEM) has been used to observe the oxide morphology directly on the surfaces of steam oxidized materials, as well as on cross-sections and exfoliated oxide flakes. This provides useful information regarding the effect of surface finish on steam oxidation processes, as well as the exfoliation of such oxide scales. 


\section{Experimental}

The nominal composition of the austenitic steel TP347HFG studied (provided by DoosanBabcock) is given in Table 1. Samples of this material were machined from heat exchanger tubes into segments $15 \mathrm{~mm}$ high and $15 \mathrm{~mm}$ wide, as indicated in Figure 1 . In order to study how the steam oxidation process is affected by the actual surface finish used in real powerplants, some samples have been used with their concave surface left in an "as-received" condition. This as-received surface results from the hot extrusion and pickling processes used in the manufacturing of TP347HFG heat exchanger tubes. The remaining five surfaces of the samples were ground to a 600 grit UK/USA standard surface finish (equivalent to P1200 European standard and with a $R_{a} \leq 0.4 \mu \mathrm{m}$ ) using SiC grinding paper. A second set of samples was prepared with all their surfaces having the same ground finish. These were used to obtain mass change baseline data for the ground surfaces. Before exposure, samples were cleaned in ultrasonic baths (with acetone and then isopropanol for 15 minutes each) before being weighed and measured with a micrometer (resolution $\pm 1 \mu \mathrm{m}$, accuracy $\pm 2 \mu \mathrm{m}$ ) to calculate their surface area.

Steam exposure tests were performed using horizontal high temperature atmospheric pressure furnaces, as illustrated in Figure 2. Inside the furnaces the samples were positioned in alumina crucibles. To generate a $100 \%$ steam environment, water was circulated into the furnace and collected again on exiting. The water reservoir for the furnace contained deionized water which was continuously de-oxygenated by bubbling oxygen free nitrogen through it. Multiple furnaces operating at $600,650,700,750$ or $800^{\circ} \mathrm{C}$ were used to expose samples for up to 2500 hours. Samples with all of their surfaces ground to a 600 grit surface finish were exposed to steam at $650,700,750$ and $800^{\circ} \mathrm{C}$, whereas samples with the asreceived surface finish on their concave surface were exposed at $600,650,700$ and $750^{\circ} \mathrm{C}$. The furnaces were shut down every 250 hours to enable net mass change data to be gathered for each sample. The mass change associated with the steam oxidation of the as-received concave surface was calculated by eliminating the mass change associated with the ground surfaces.

Scanning electron microscopy (SEM) in association with energy dispersive X-ray (EDX) analysis was used for post-exposure characterization of the oxidized surfaces, cross-sections and exfoliated oxide flakes (recovered from the crucibles in which the different samples were standing). After having characterized the oxides formed on each sample's surface, the different samples were mounted to form cross-sections using low shrinkage epoxy resin filled with ballotini (glass spheres of 40-70 $\mu \mathrm{m}$ diameter) and ground/polished to a $1 \mu \mathrm{m}$ grit surface finish using standard SiC papers and diamond pastes with oil lubricant. 
3. Results and discussion

\subsection{Mass change data}

The mass change results associated with the steam oxidation of the ground and as-received surface finishes are presented in

Figure 3. The results obtained are the same order of magnitude as those previously reported $[4,5]$.

The mass change data for samples with ground surfaces showed low steam oxidation rates (

Figure 3 (a)). During 650 and $700{ }^{\circ} \mathrm{C}$ exposures there was no evidence of scale exfoliation, and at $750^{\circ} \mathrm{C}$ this became significant only after 2000 hours. However, at $800^{\circ} \mathrm{C}$ the scale exfoliation process becomes dominant in the weight change data, meaning that exfoliation occurred at a faster rate than the oxidation processes.

The mass change data of samples with surfaces that had both ground and as-received surface finish were processed to remove the effect of the ground surfaces. Thus, the results presented in

Figure 3 (b) are for the as-received surface only. These show mass losses at both 700 and $750^{\circ} \mathrm{C}$ due to scale exfoliation; in fact at $750^{\circ} \mathrm{C}$ the exfoliation process is dominant from the first cycle so that only mass losses were recorded.

After short exposure times, grinding was observed to be beneficial to steam oxidation resistance in terms of mass change (

Figure 3). Moreover no oxide products were observed in the crucibles containing the exposed material before 500 hours, which demonstrated that at short time the recorded mass change is only affected by the oxide growth process. After 500 hours, ground surfaces show a mass gain higher than the as-received surfaces. This observation can be due to the scale exfoliation process occurring on the as-received surface contributing in net mass loss. The concept of scale exfoliation and regrowth employed developed by Sabau et al. [8] is well illustrated by what happen on fully ground TP347HFG at $750^{\circ} \mathrm{C}($

Figure $3(a))$. Mass change associated with this test shows only small variations, with alternating mass gain and mass loss from 500 hours to 2000 hours.

When examining the net mass change data from the different samples, it can be observed that the exfoliation process becomes significant at and above $700^{\circ} \mathrm{C}$. In order to obtain a better understanding of the exfoliation process, the morphology of the oxides formed on the 
TP347HFG samples were examined, as well as exfoliated oxide flakes that have been recovered. 


\subsection{Oxide morphology}

Figure 4 shows the surface scale morphologies developed on samples with ground and asreceived surfaces.

In the temperature range $600-700^{\circ} \mathrm{C}$, after 2500 hours of steam exposure, the as-received surface has formed a thin $\mathrm{Cr}$-rich oxide layer and Fe-rich nodules. However after 2500 hours at $750^{\circ} \mathrm{C}$ the oxide morphology changes (Figure 4 (i)). This surface is mostly covered with Ferich oxides although an oxide layer rich in chromium and iron can be observed in areas from which the Fe-rich oxide has exfoliated. The absence of the thin and protective chromia layer indicates that oxidation has moved beyond the formation of protective oxide scales; potentially due to the local sub-scale depletion of chromium.

At all temperatures in the range $600-800^{\circ} \mathrm{C}$ and up to 2500 hours, the ground surface is associated with the formation of a $\mathrm{Cr}$-rich oxide layer on its surface (Figure 4). This layer is mostly thin and uniform, but Fe-rich nodules are also found on this surface. The sizes of the Fe-rich nodules formed are much smaller than those observed on the oxidized as-received surface. Evidence of scale exfoliation from the ground surfaces could also be observed. For example, small areas of the oxides formed on the ground sample's surface at $700^{\circ} \mathrm{C}$ have exfoliated and it is then possible to see the material's underlying surface from where the exfoliation has occurred (Figure $4(\mathrm{~h})$ ). This underlying surface does not have areas of residual oxides. It is believe that this scale exfoliation is a result of stress relieving processes occurring at the surfaces of samples during the cooling down of the furnace at the end of a steam exposure cycle. At $750^{\circ} \mathrm{C}$ (Figure 4 (j)) the morphology of the oxide formed on the surface is different from that seen at lower temperatures, with larger Fe-rich areas of oxide present.

Exfoliated oxide scales have been recovered from the crucibles in which the samples were exposed. SEM imaging was used to characterize the morphology of the different surfaces of the exfoliated flakes (Figure 5). It was believed that observing the exfoliated oxide flakes might provide some useful information to explain the exfoliation mechanism, such as zones of stress or zones of high porosity. The exfoliation process occurred from within the oxide layers. On the original steam-side interface of oxide flakes, oxide crystals of different shapes can be observed (Figure 5 (a) and (b)). This oxide has been identified as magnetite. In addition, needles or plates of oxide can be observed and these are characteristic of $\mathrm{Fe}_{2} \mathrm{O}_{3}$ formation [9]. On the other side of the flake (i.e., side which was in contact with the oxide remaining attached to the material's surface) different zones can be visualized (Figure $5(e)$ and (f)):

- Smooth areas: that could be due to rapid fracture processes from the propagation of cracks driven by thermal contraction [5] causing stress during cool down. This could be considered for a potentially strong interface just prior to the exfoliation process. 
- Porous/more crystalline areas: These zones are representative of the porosity in the Fe-rich part of the oxide scale. These could be considered as potentially weak interfaces prior to the exfoliation process as these gaps within the oxide scale reduce the contact area between the upper and lower oxide layers. The oxide grains seem to possess sharper edges which could be due to brittle fractures as a result of stress build up in the scales. Large cavities can also be observed in some cases (Figure 5 (e)).

Observation of the edges of the exfoliated oxide flakes (Figure 5 (c) and (d)) have shown that the grains located towards the metal/oxide side of the flake are columnar (4-10 $\mu \mathrm{m}$ long) and large (2.5-5 $\mu \mathrm{m}$ in width). However, at the steam/oxide interface, the oxide grains are a lot smaller in size $(<1 \mu \mathrm{m})$. The observation of large columnar magnetite grains present in the oxide scales with smaller magnetite grains on top of it is consistent with the literature [5] where a double layer of magnetite has been reported.

Steam exposure tests at $800^{\circ} \mathrm{C}$ are in progress. Preliminary observations of exfoliated oxide flakes from these exposures are shown in Figure 6 and Figure 7. These show that there are occasionally large growing magnetite grains, between 80 and $160 \mu \mathrm{m}$ long, on ground surfaces exposed to steam at $800^{\circ} \mathrm{C}$ after 500 and 1500 hours respectively. Lyta et al. [10] reported that, for austenitic steels such as TP347HFG, surface magnetite grain sizes could became larger with increasing oxidation time.

Figure 8 shows examples of large Fe-rich oxide grains formed during 1500 hours of steam exposure at $800^{\circ} \mathrm{C}$. It was observed that smaller oxide grains were present between the large crystals of magnetite. The reasons for the formation of such large grains and for the mechanisms associated with their growth are still to be determined. The possible formation of such oxide grains needs to be taken into account for the development of a model describing oxide exfoliation.

Since these long magnetite grains were not observed on oxide flakes exfoliated from tests at 700 and $750^{\circ} \mathrm{C}$, it would appear that they are characteristic of steam oxidation processes occurring at higher temperatures (such as $800^{\circ} \mathrm{C}$ ). 


\subsection{Cross-sectional imaging}

Cross-sections of TP347HFG oxidized for 2500 hours under different steam temperature have been examined. Figure 9 illustrates the multi-layered oxide formed on the as-received surfaces. In the temperature range $600^{\circ} \mathrm{C}-700^{\circ} \mathrm{C}$, irregular oxide scales are observed and this can be explained by the nodular growth of Fe-oxide due to the breaking down of the protective $\mathrm{Cr}$-rich oxide layer. However, at $750^{\circ} \mathrm{C}$ a thicker oxide is observed. Thus the nodular breakdown of the protective chromia layer seems to have happened before 2500 hours. The further evolution of this oxide scale will no longer be affected by the original protective chromia layer. By contrast, for the ground surfaces, a very thin layer of $\mathrm{Cr}$-rich oxide is observed at all temperatures. Different contrasts from the oxide layers can be observed, but no differences in compositions were revealed by EDX analysis. The thin $\mathrm{Cr}$-rich layer developed on ground surfaces increases the steam oxidation resistance of the material and delays or prevents the initiation and growth of Fe-rich oxides. Several works $[4,5,11]$ explain that the beneficial effects from a machined surface comes from the formation of a large number of dislocations beneath the ground surface. Dislocations act as fast diffusion paths for chromium, enhancing its rate of diffusion towards the surface of the material. This allows rapid formation of a protective $\mathrm{Cr}$-rich oxide layer. These dislocations may also cause recrystallization resulting in grain boundaries which also enhance the rate of diffusion.

Cross-sectional images allow more information to be obtained regarding the exfoliation process. Figure 9 shows that cracks and voids are located inside the magnetite layer and the Fe-rich nodules. Such cracks represent weak interfaces from which exfoliation can originate. They can appear during the cooling down stage of the furnaces' operation and can also result from the shrinkage of the resin used during cross-sectional mounting (although a filled, low shrinkage resin was deliberately used to avoid this effect). Nevertheless, such cracks remain representative of weaknesses in the oxide layers.

EDX analysis has been performed to identify the different elements present in the multilayered oxide scales formed on the as-received surfaces after 2500 hours steam exposure at 650 and $750^{\circ} \mathrm{C}$. Figure 10 illustrates an example of the composition of the different oxides forming a nodule after 2500 hours of steam exposure at $650^{\circ} \mathrm{C}$. This shows that a thin layer of chromium-rich oxide was formed at the oxide/metal interface, with ( $\mathrm{Fe}, \mathrm{Ni}, \mathrm{Cr}$ )-containing oxide present in the inner part of the nodule. Chromium is enriched in this part of the oxide scale. Magnetite was found to form the outer part of the oxide nodule. Haematite is sometimes found on top of the magnetite oxide under steam oxidation conditions but there is no evidence of its presence here. This variable behaviour with respect to haematite formation has occasionally been noted $[5,12,15]$.

The oxide scale after total breakdown of the protective chromia layer on the as-received surface is presented in Figure 11 after 2500 hours of steam exposure at $750^{\circ} \mathrm{C}$. The multi- 
layered oxide present is also composed of an outer magnetite layer on top of a $\mathrm{Ni}$-Fe oxide. Underneath, a $\mathrm{Cr}$-rich $(\mathrm{Fe}, \mathrm{Ni}, \mathrm{Cr}$ ) oxide makes up the inner layer with a higher chromium content oxide at the metal/oxide interface. Such multi-layered oxide structures are characteristic of the steam oxidation of austenitic steels in steam [5]. Jianmin et al. [13,14] reported similar multi-layered oxide scales and explained how the oxide scale develops after the break down of the protective chromia layer and how the different oxides formed influence the steam oxidation process. They pointed out that the original chromium layer is transformed in an inner $\mathrm{Cr}$-rich $(\mathrm{Fe}, \mathrm{Ni}, \mathrm{Cr}$ ) spinel oxide layer with Fe-rich oxides growing at its surface. The inner layer grows inwardly until it reaches a grain boundary where a protective chromia layer is formed resulting in the slowing down of the oxidation rate. When this protective layer breaks down, inward oxidation continues until the oxidation front reaches another grain boundary, etc. EDX analysis allowed measurement of the thickness of the inner oxide grown after 2500 hours of steam exposure in the temperature range $600-750^{\circ} \mathrm{C}$. It appears the maximum thickness of the $\mathrm{Cr}$-rich inner oxide measured is between 15 and 30 $\mu \mathrm{m}$. The grain size of the studied material was determined by measuring the longest grain dimension for 261 grains (from 5 images). The average grain size is $16 \mu \mathrm{m}$, with $90 \%$ of values measured falling between 8 and $30 \mu \mathrm{m}$. This compares well to the grain size of $11 \mu \mathrm{m}$ found for the sample using the linear intercept method. With this grain size it is sensible to expect the oxide scale developed has followed the different steps reported by Jianmin et al. $[13,14]$.

It is interesting to point out that the laboratory steam exposure tests presented in this paper result in the formation of similar oxide layers to those reported in field exposure tests $[13,14]$. These results show the relevance of atmospheric pressure exposure performed without the presence of heat flux. Indeed the laboratory tests in this study and the field exposure tests described in the literature $[13,14]$ result in the same multi-layered oxide scales and scale compositions. In particular, the growth of the inner oxide scale in both instances is limited at times within individual grains, resulting in an uneven oxide/metal interface. 


\section{Conclusions}

The effects of steam oxidation on TP347HFG have been observed for up to 2500 hours in the temperature range $600-800^{\circ} \mathrm{C}$ for two different surface finishes. The material with a ground (600 grit UK/USA standard) surface finish had better steam oxidation resistance than the asreceived surface. Compared to the as-received surface finish, materials with ground surfaces exhibited less mass gain during steam oxidation. More importantly, exfoliation of the oxide scales happened at higher temperatures and after longer exposure times for the ground surfaces.

In terms of oxide composition and morphology, the steam oxidation of the ground surface is associated with the formation of a thin chromium-rich oxide layer with some small iron-rich nodules breaking through this protective oxide. In contrast, steam oxidized as-received surfaces exhibit a less protective chromium-rich layer and large iron-rich nodules in the temperature range $600-700^{\circ} \mathrm{C}$. At $750^{\circ} \mathrm{C}$ the chromium rich oxide is no longer visible and instead a multi-layered oxide forms. The oxide layer composition, and the distribution of the different oxides, formed in these laboratory exposures show similar features compared to reported field exposure experiments.

The oxide morphologies observed on exfoliated oxide flakes reveal large magnetite grains under a layer of smaller, more equiaxed grains. On the surface that had been in contact with the metal, there were different areas that could be representative of potentially strong and weak areas of the metal/oxide interfaces. Further investigations of these features are continuing.

\section{Acknowledgements}

The authors acknowledge the support of the Engineering and Physical Research Council (EPSRC) for their support for the project - Flexible and Efficient Power Plant: Flex-E-Plant (Grant number: EP/K021095/1). They also thank the following partners for their the valuable contributions: GE Power, Doosan Babcock Limited, Centrica plc., EDF Energy (West Burton Power) Limited., Uniper Technology Limited, Goodwin Steel Castings Limited, NPL Management Limited, R-MC Power Recovery Limited., RWE Generation UK plc., Scottish and Southern Energy (SSE) plc., Siemens Industrial Turbomachinery, and TWI Limited. 


\section{References}

[1] Presidency of European Council, "Conclusion of the Brussels European Council 8/9 March 2007 Presidency conclusions," vol. 7224/1/07, no. REV1, 2007.

[2] International Energy Agency, "Energy and Climate Change," World Energy Outlook Spec. Rep., 2015.

[3] G. R. Holcomb, "High Pressure Steam Oxidation of Alloys for Advanced UltraSupercritical Conditions," Oxid. Met., vol. 82, pp. 271-295, 2014.

[4] H. J. Grabke, S. Strauss, E. Pippel, and J. Woltersdorf, "Effects of Grain Size, Cold Working, and Surface Finish on the Metal-Dusting Resistance of Steels," Oxid. Met., vol. 50, no. 314, pp. 241-254, 1998.

[5] R. B. Dooley, "Program on Technology Innovation : Oxide Growth and Exfoliation on Alloys Exposed to Steam," EPRI Final Rep., vol. 1013666, 2007.

[6] R. Viswanathan, J. Sarver, and J. M. Tanzosh, "Boiler Materials for Ultra-Supercritical Coal Power Plants - Steamside Oxidation," J. Mater. Eng. Perform., vol. 15, no. June, pp. 255-274, 2006.

[7] G. S. Was, P. Ampornrat, G. Gupta, S. Teysseyre, E. A. West, T. R. Allen, K. Sridharan, L. Tan, Y. Chen, X. Ren, and C. Pister, "Corrosion and stress corrosion cracking in supercritical water," J. Nucl. Mater., vol. 371, no. 1-3, pp. 176-201, 2007.

[8] A. S. Sabau, I. G. Wright, and J. P. Shingledecker, "Oxide Scale Exfoliation and Regrowth in TP347H Superheater Tubes," Mater. Corros., vol. 63, no. 10, pp. 896908, 2012.

[9] Z W Liu, M L Zong, and C M Tang, "Large-scale oxide nanostructures grown by thermal oxidation," IOP Conf. Ser. Mater. Sci. Eng., vol. 60, 2014.

[10] Lyta, M. Ueda, K. Kawamura, M. Takeyama, and T. Maruyama, "Microstructure Development of Oxide Scale during Steam Oxidation of the $\mathrm{Fe}-20 \mathrm{Cr}-30 \mathrm{Ni}-2 \mathrm{Nb}$ ( at \% ) Austenitic Steel at 1073 K," Mater. Trans., vol. 54, no. 12, pp. 2276-2284, 2013.

[11] S. Tuurna, S. Y. Olli, P. Auerkari, E. C. Zabetta, and K. Vänskä, "Influence of Temperature and Surface Treatment on Steamside Oxidation," in 10th Liege Conference on Materials for Advanced Power Engineering, 2014.

[12] H. Abe, S. M. Hong, and Y. Watanabe, "Oxidation behavior of austenitic stainless steels as fuel cladding candidate materials for SCWR in superheated steam," Nucl. Eng. Des., vol. 280, pp. 652-660, 2014.

[13] J. Jianmin, M. Montgomery, O. H. Larsen, and S. a. Jensen, "Investigation on steam oxidation behaviour of TP347H FG Part 1: Exposure at 256 bar," Mater. Corros., vol. 56, no. 7, pp. 459-467, 2005.

[14] J. Jianmin, M. Montgomery, O. H. Larsen, and S. a. Jensen, "Investigation on steam oxidation behaviour of TP347H FG Part 2: Exposure at 91 bar," Mater. Corros., vol. 56, 
no. 7, pp. 459-467, 2005.

[15] M. Lukaszewicz, N. J. Simms, T. Dudziak, and J. R. Nicholls, "Effect of Steam Flow Rate and Sample Orientation on Steam Oxidation of Ferritic and Austenitic Steels," Oxid. Met., vol. 79, pp. 473-483, 2013. 
Table 1: Nominal composition of TP347HFG (in weight \%).

\begin{tabular}{|c|c|c|c|c|c|c|}
\hline \multirow{2}{*}{ Alloy } & \multicolumn{6}{|c|}{ Element (weight \%) } \\
\cline { 2 - 7 } & $\mathrm{Fe}$ & $\mathrm{Ni}$ & $\mathrm{Cr}$ & $\mathrm{C}$ & $\mathrm{Si}$ & $\mathrm{Mn}$ \\
\hline TP347HFG & $\mathrm{Bal}$ & 11.5 & 18.4 & 0.1 & 0.4 & 1.5 \\
\hline
\end{tabular}




\section{Figure captions:}

Figure 1: Schematic diagram of the sample shape used for this study $(H=15 \mathrm{~mm}, W=15$ $\mathrm{mm})$.

Figure 2: Schematic of the high temperature atmospheric and isothermal steam furnace used for steam exposure tests [15].

Figure 3: Mass change per unit of area during steam oxidation of (a) ground and (b) asreceived surfaces of TP347HFG for a range of temperatures.

Figure 4: SEM imaging of the different surfaces of TP347HFG before and after steam exposure: (a) as-received and (b) ground surfaces before exposure; (c) as-received and (d) ground surfaces at $600^{\circ} \mathrm{C}$ after 2500 hours; (e) as-received and (f) ground surfaces at $650^{\circ} \mathrm{C}$ after 2500 hours; (g) as-received and (h) ground surfaces at $700^{\circ} \mathrm{C}$ after 2500 hours; (i) asreceived and (j) ground surfaces at $750^{\circ} \mathrm{C}$ after 2500 hours.

Figure 5: SEM imaging of exfoliated oxide flakes: original steam side at (a) $700^{\circ} \mathrm{C}$ and (b) $750^{\circ} \mathrm{C}$; image of the side of a flake at (c) $700^{\circ} \mathrm{C}$ and (d) $750^{\circ} \mathrm{C}$; side of the flake which was in contact with the remaining oxide at the material's surface at (e) $700^{\circ} \mathrm{C}$ and (f) $750^{\circ} \mathrm{C}$.

Figure 6: Two example SEM secondary electron images of the steam side of an exfoliated oxide flake at $800^{\circ} \mathrm{C}$ after 500 hours of steam exposure.

Figure 7: SEM image of the steam side of an exfoliated oxide flake at $800^{\circ} \mathrm{C}$ after 1500 hours of steam exposure.

Figure 8: Two example SEM secondary electron images of the steam side of an exfoliated oxide flake at $800^{\circ} \mathrm{C}$ after 1500 hours of steam exposure.

Figure 9: SEM imaging of cross-sections related to the different surfaces of TP347HFG after 2500 hours of steam exposure: (a) as-received and (b) ground surfaces at $600^{\circ} \mathrm{C}$; (c) asreceived and $(\mathrm{d})$ ground surfaces at $650^{\circ} \mathrm{C}$; (e) as-received and (f) ground surfaces at $700^{\circ} \mathrm{C}$; (g) as-received and $(\mathrm{h})$ ground surfaces at $750{ }^{\circ} \mathrm{C}$.

Figure 10: EDX analysis on cross-section of the as-received surface after 2500 hours of steam oxidation at $650^{\circ} \mathrm{C}$ : (a) back scattered electron image, with accompanying (b) $\mathrm{Fe}$, (c) $\mathrm{Ni}$ and (d) Cr maps.

Figure 11: EXD analysis on cross-section of the as-received surface after 2500 hours of steam oxidation at $750^{\circ} \mathrm{C}$ : (a) back scattered electron image, with accompanying (b) $\mathrm{Fe}$, (c) $\mathrm{Ni}$ and (d) Cr maps. 


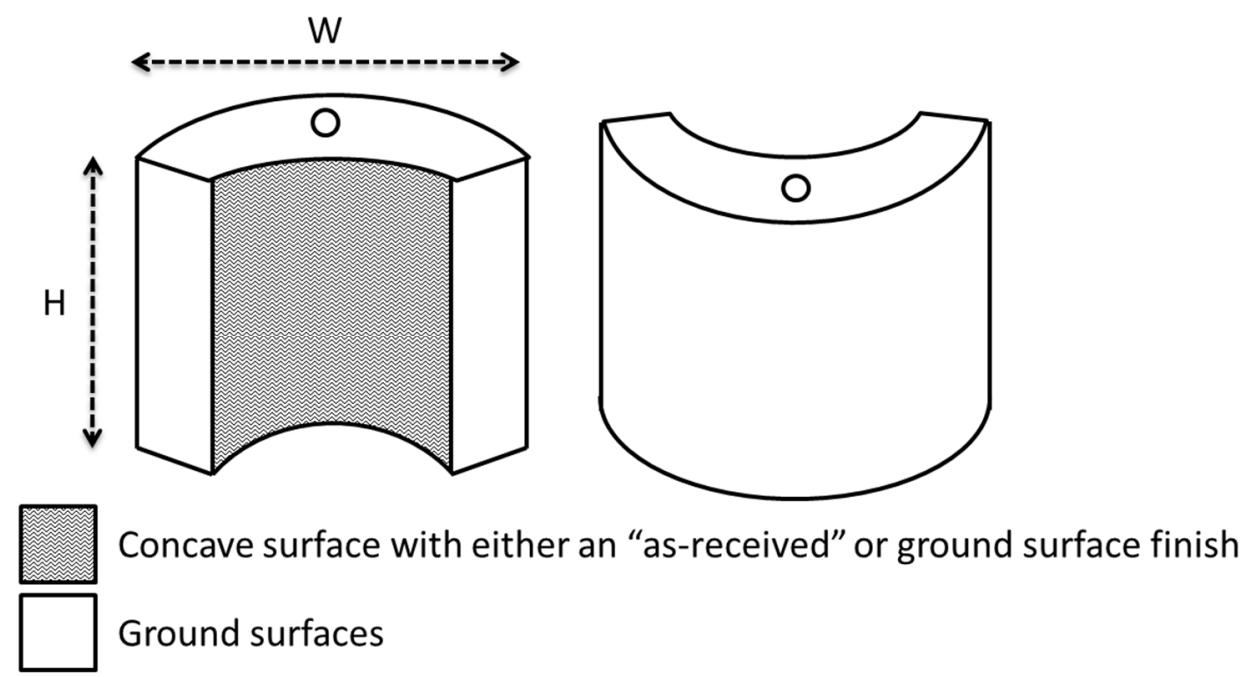

Figure 1: Schematic diagram of the sample shape used for this study $(H=15 \mathrm{~mm}, \mathrm{~W}=15$ $\mathrm{mm})$.

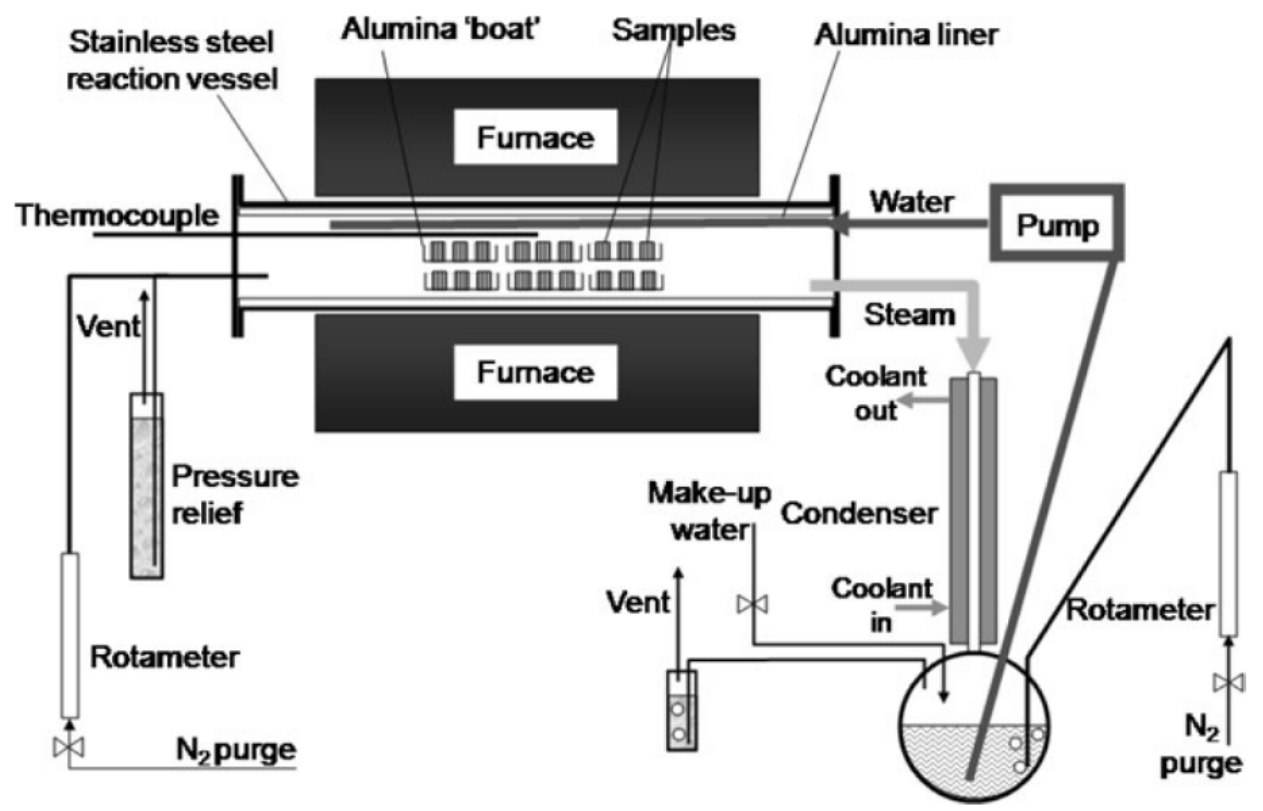

Figure 2: Schematic of the high temperature atmospheric and isothermal steam furnace used for steam exposure tests [15]. 

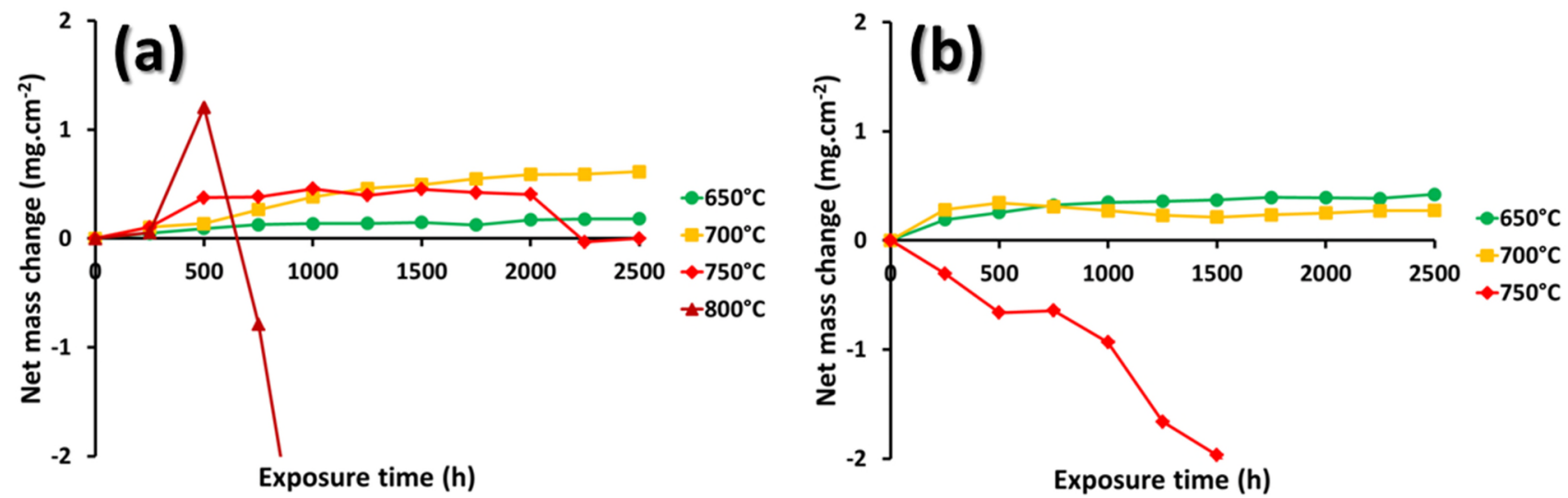

Figure 3: Mass change per unit of area during steam oxidation of (a) ground and (b) as-received surfaces of TP347HFG for a range of temperatures. 


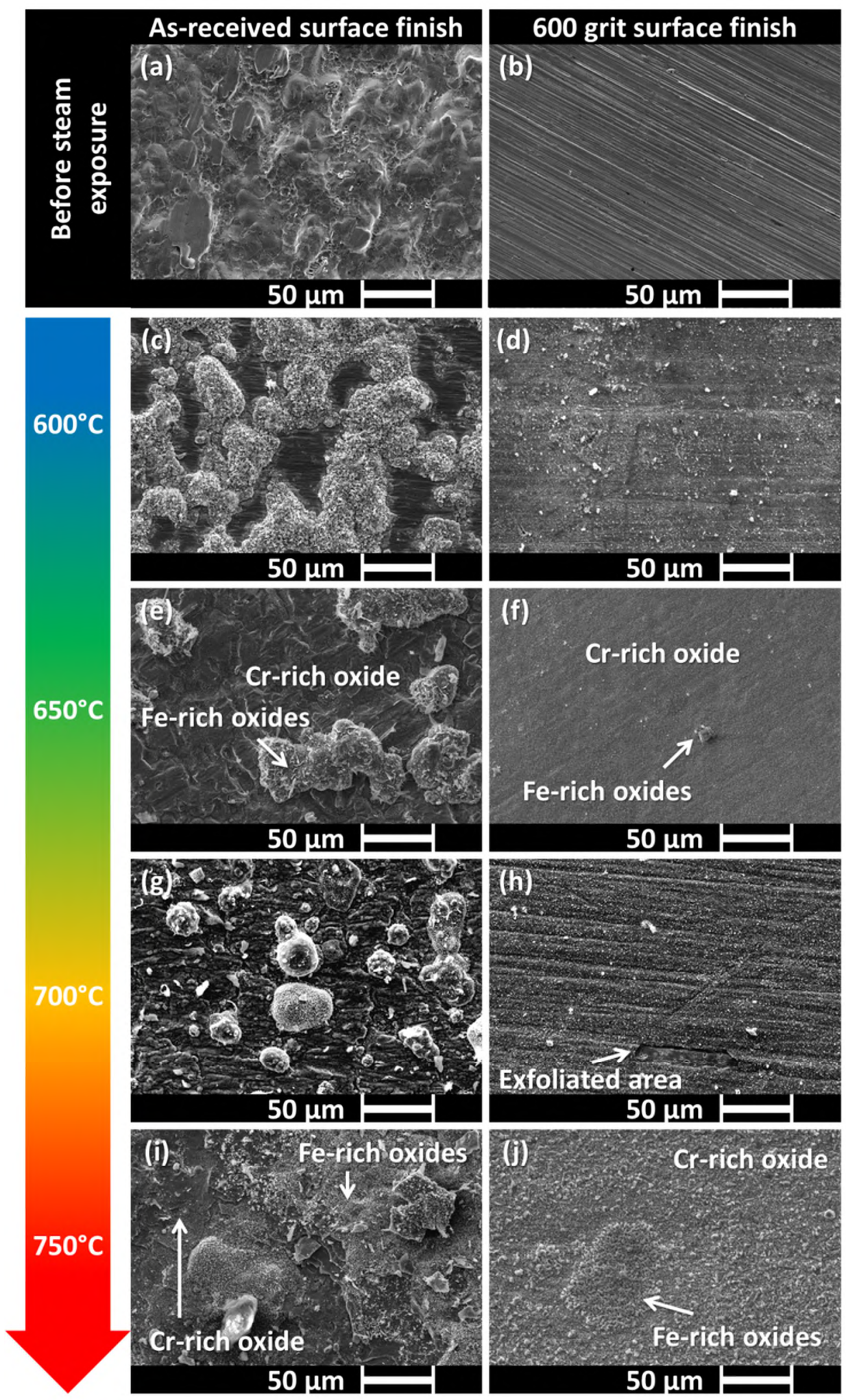

Figure 4: SEM imaging of the different surfaces of TP347HFG before and after steam exposure: (a) as-received and (b) ground surfaces before exposure; (c) as-received and (d) ground surfaces at $600^{\circ} \mathrm{C}$ after 2500 hours; (e) as-received and (f) ground surfaces at $650^{\circ} \mathrm{C}$ after 2500 hours; (g) as-received and (h) ground surfaces at $700^{\circ} \mathrm{C}$ after 2500 hours; (i) asreceived and (j) ground surfaces at $750^{\circ} \mathrm{C}$ after 2500 hours. 

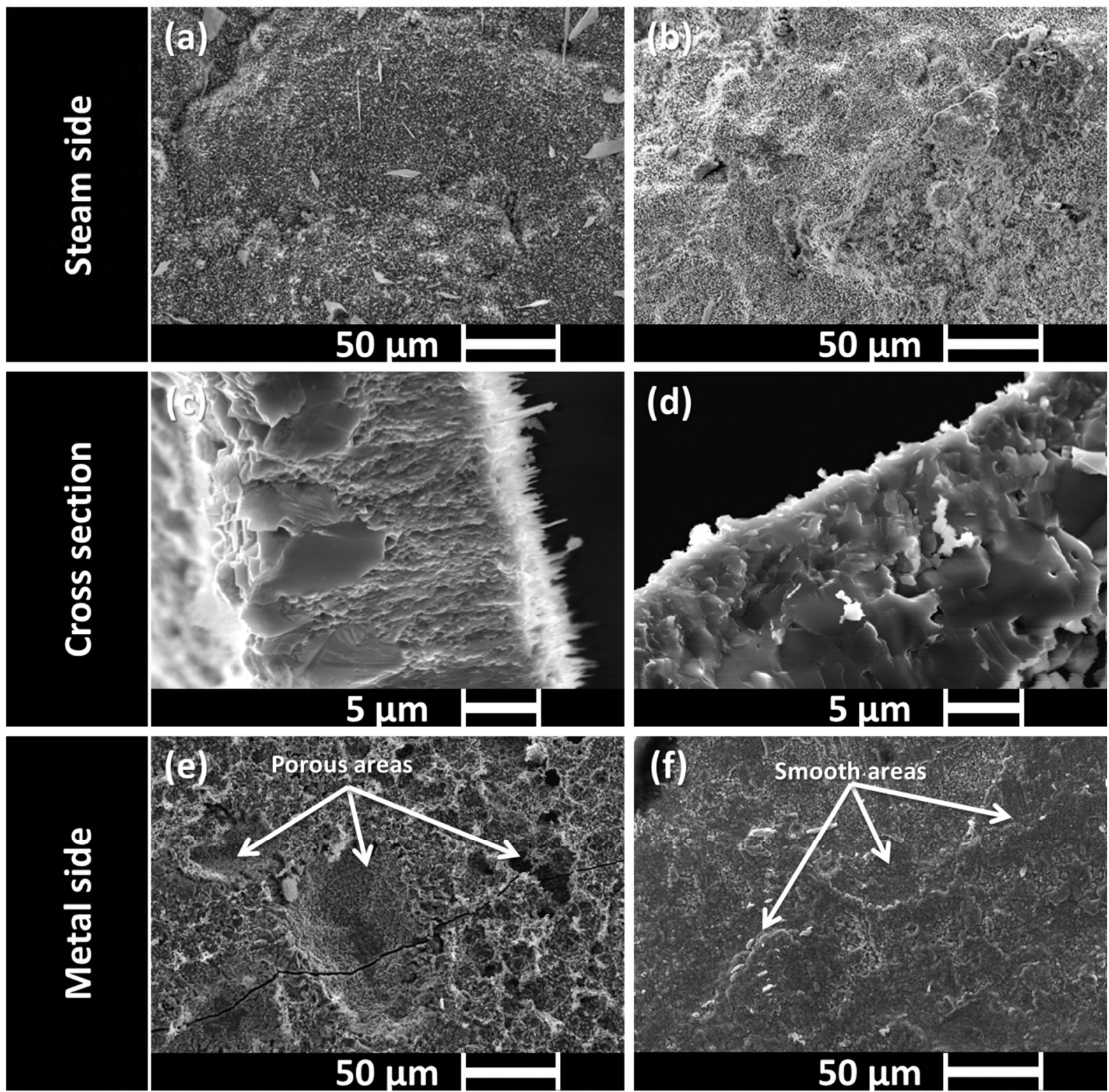

Figure 5: SEM imaging of exfoliated oxide flakes: original steam side at (a) $700^{\circ} \mathrm{C}$ and (b) $750^{\circ} \mathrm{C}$; image of the side of a flake at $(c) 700^{\circ} \mathrm{C}$ and (d) $750^{\circ} \mathrm{C}$; side of the flake which was in contact with the remaining oxide at the material's surface at (e) $700^{\circ} \mathrm{C}$ and (f) $750^{\circ} \mathrm{C}$. 

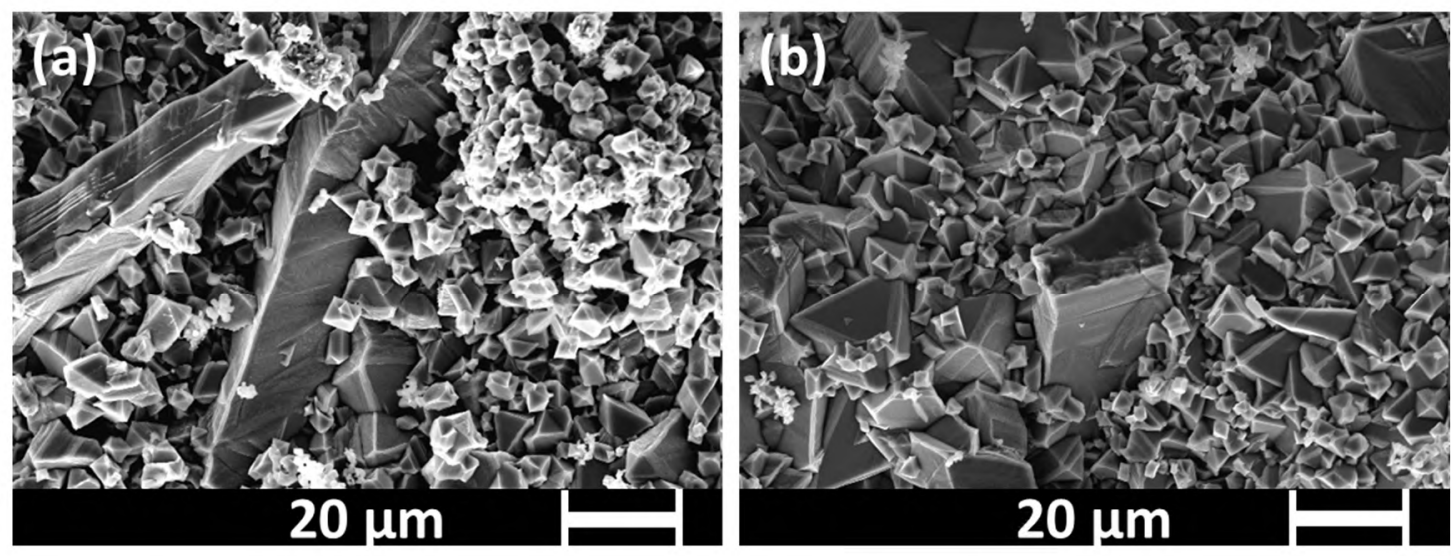

Figure 6: Two example SEM secondary electron images of the steam side of an exfoliated oxide flake at $800^{\circ} \mathrm{C}$ after 500 hours of steam exposure.

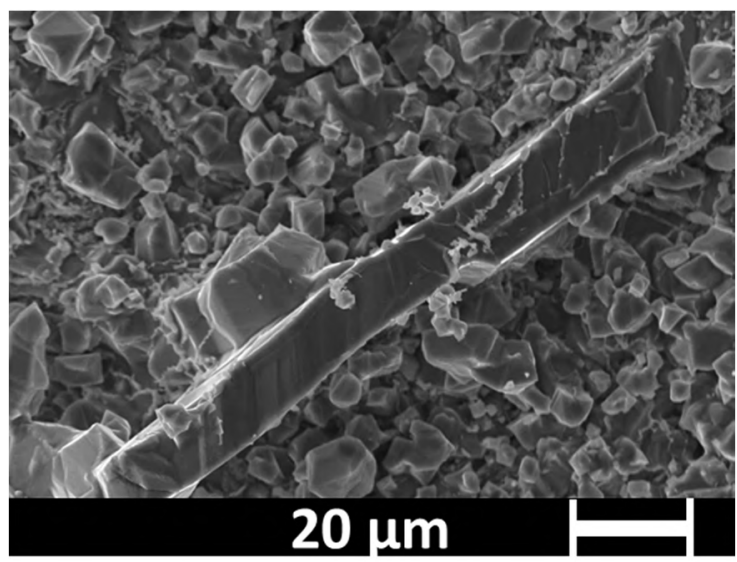

Figure 7: SEM image of the steam side of an exfoliated oxide flake at $800^{\circ} \mathrm{C}$ after 1500 hours of steam exposure. 

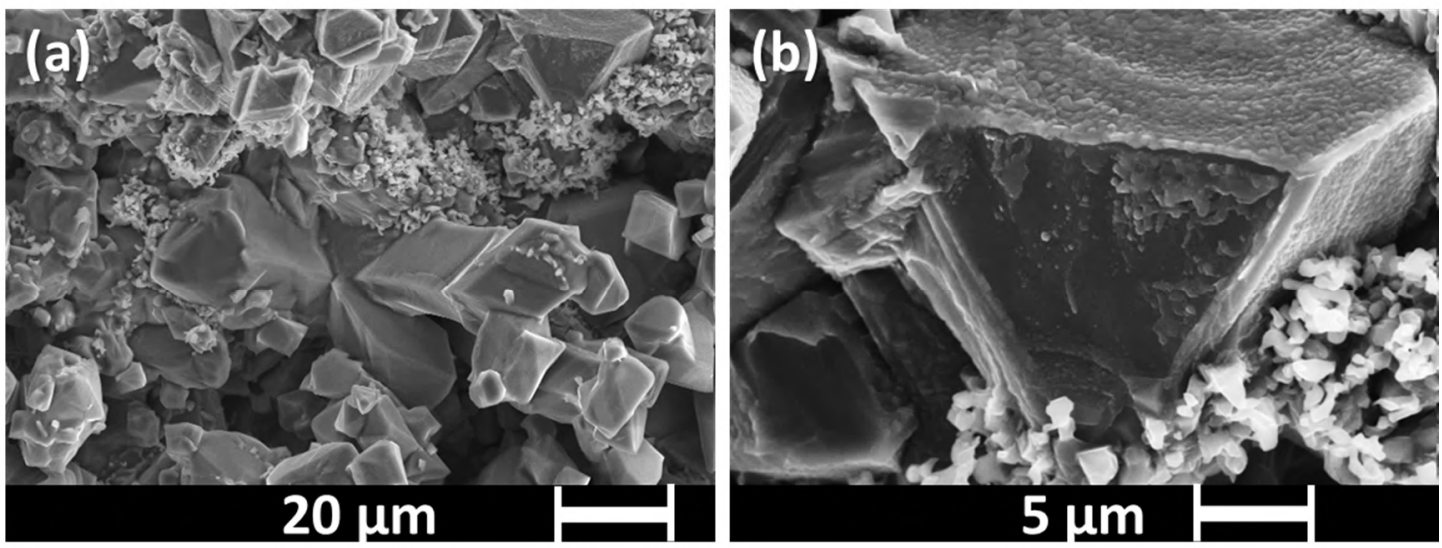

Figure 8: Two example SEM secondary electron images of the steam side of an exfoliated oxide flake at $800^{\circ} \mathrm{C}$ after 1500 hours of steam exposure. 


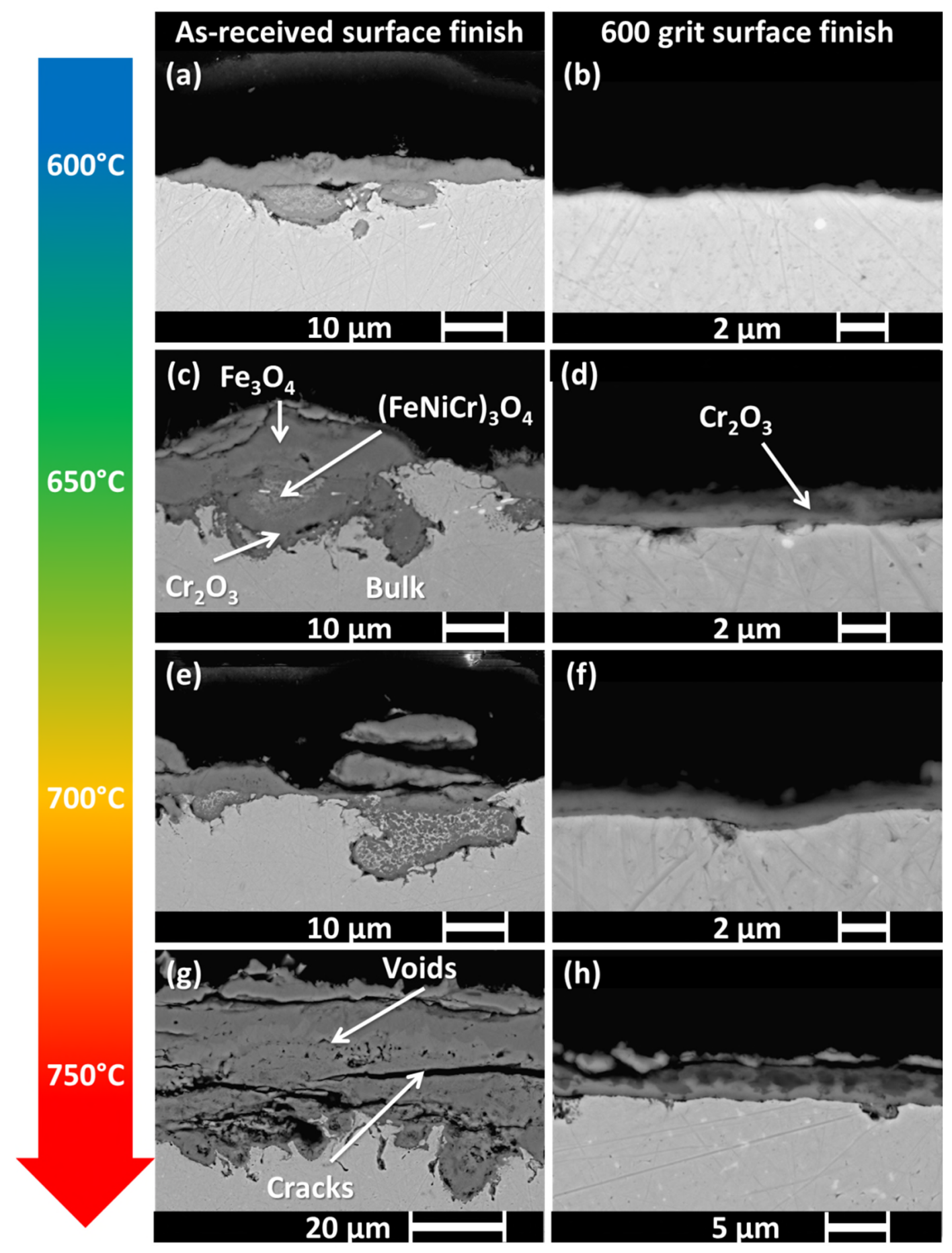

Figure 9: SEM imaging of cross-sections related to the different surfaces of TP347HFG after 2500 hours of steam exposure: (a) as-received and (b) ground surfaces at $600^{\circ} \mathrm{C}$; (c) asreceived and (d) ground surfaces at $650^{\circ} \mathrm{C}$; (e) as-received and (f) ground surfaces at $700^{\circ} \mathrm{C} ;(\mathrm{g})$ as-received and $(\mathrm{h})$ ground surfaces at $750^{\circ} \mathrm{C}$. 


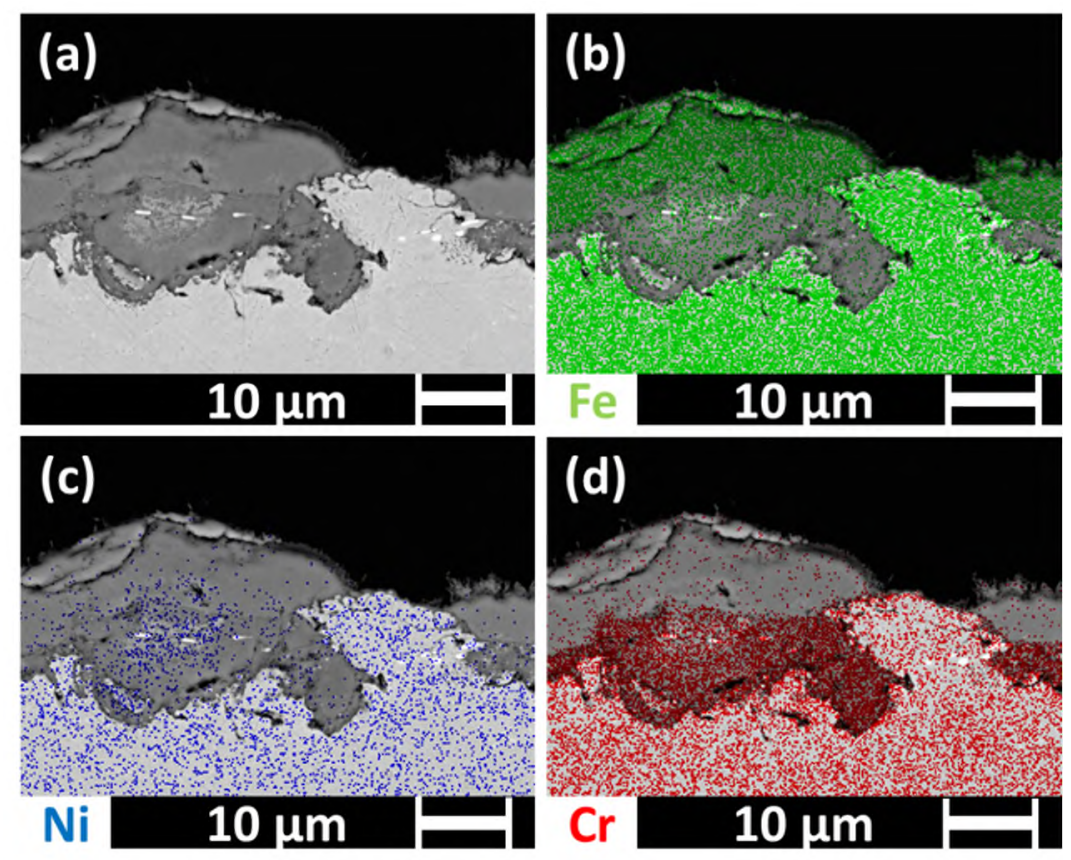

Figure 10: EDX analysis on cross-section of the as-received surface after $\mathbf{2 5 0 0}$ hours of steam oxidation at $650^{\circ} \mathrm{C}$ : (a) back scattered electron image, with accompanying (b) $\mathrm{Fe}$, (c) $\mathrm{Ni}$ and (d) Cr maps.
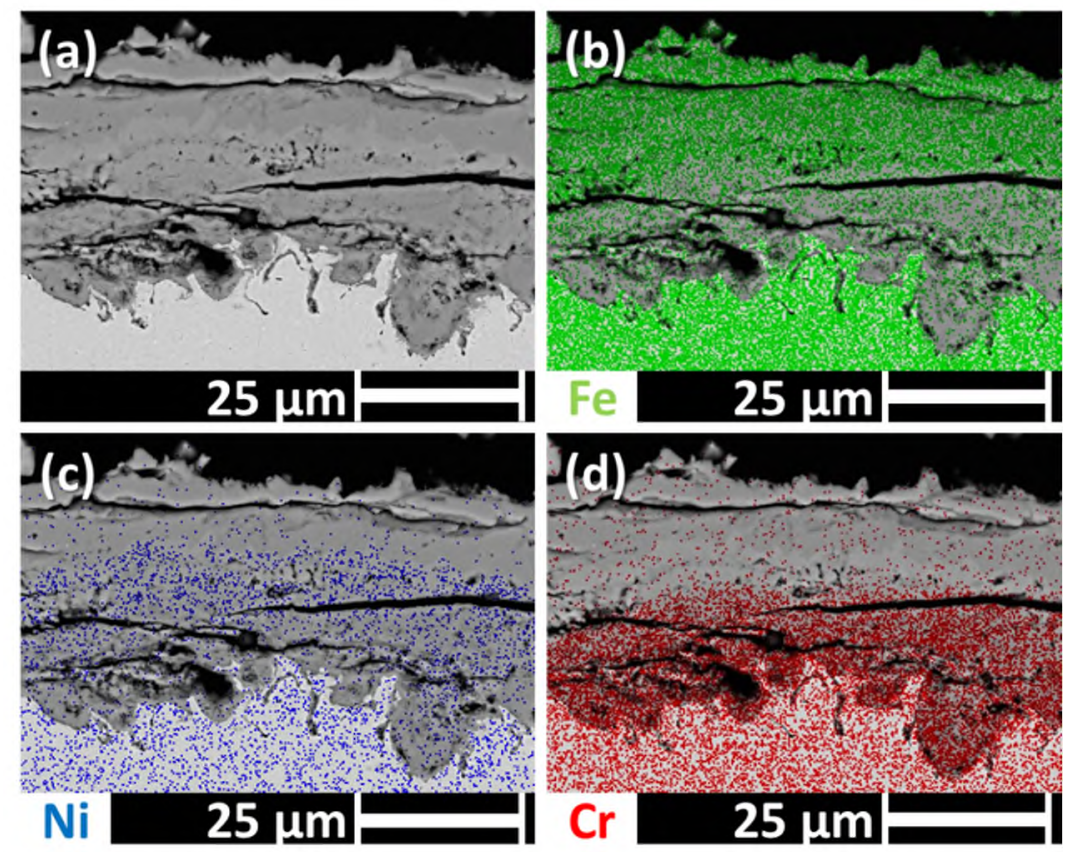

Figure 11: EXD analysis on cross-section of the as-received surface after 2500 hours of steam oxidation at $750^{\circ} \mathrm{C}$ : (a) back scattered electron image, with accompanying (b) $\mathrm{Fe}$, (c) $\mathrm{Ni}$ and (d) Cr maps. 